\title{
DOCUMENTATION OF PATIENTS' PARTiCIPATION IN CARE AT THE END OF LIFE
}

\section{Irma Lindström, Fannie Gaston-Johansson and Ella Danielson}

Key words: content analysis; documentation; end of life; health care records; patient participation

The aim of this study was to describe how patients' participation in the care they received was documented in their health care records during the last three months of their lives. Two hundred and twenty-nine deceased adult persons were randomly identified from 12 municipalities in a Swedish county and their records were selected from different health care units. Content analysis was used to analyse the text. Four categories of patient participation were described: refusing offered care and treatments; appealing for relief; desire for everyday life; and making personal decisions. The most common way for these patients to be involved in their care at the end of their life was by refusal of the treatment and care offered. Characteristic of the different ways of participation were the diverse activities represented. The description of patients' involvement in their life situation at this time indicated their dissociation from the health care offered more than consenting to it.

\section{Introduction}

In Sweden, as in many other countries in the western world, patients have the freedom and right to make their own choices regarding health care. This makes it necessary for health care professionals to collaborate directly with patients. Autonomous patients are expected to become involved and to participate in their own health care. This ideal situation is regulated in the Swedish Health Care Act and related to care at the end of life. $^{1,2}$

Many people want to be involved in what happens around them and to participate in daily activities, even while making allowance for the circumstances in which they find themselves at the end of their life. When provided with the opportunity to choose, most people's choice of care options is for an appropriate death. ${ }^{3}$ It is important that the quality of care at the end of life is based on individuals' perspective, which should be achieved through a process whereby patients participate in the decision-making

Address for correspondence: Irma Lindström, The Sahlgrenska Academy at Göteborg University, Institute of Nursing, Box 457, SE 40530 Göteborg, Sweden. Tel: + 4631 7736065; Fax: + 4631 7736050; E-mail: Irma.Lindstrom@fhs.gu.se 
process. ${ }^{4}$ Because of these patients' conditions and for ethical reasons it is not always easy to study or evaluate any lack of agreement between patients and clinicians. ${ }^{5}$

The result of the shift from paternalism to collaboration has left patients with little guidance about how to make optimal decisions about their care and treatments. ${ }^{5}$ One of the most significant aspects of patient participation research is determining how health care professionals can best aid and support patients in decision-making processes. Interaction between health care professionals and patients concerning the type and extent of medical treatment that patients desire is a crucial aspect of the process. ${ }^{6}$ Previous findings suggest a certain incongruity between what clinicians believe a patient should know and what the patient actually wants to know. ${ }^{5}$

No exact definition of patients' participation in health care at the end of life can be found in the literature, but it implies on the whole that they are involved and have control of their health care proceedings. Most definitions are based on patient-centred care, in which patients are autonomous and participate, and are involved in clinical decisions. $^{7-10}$ Autonomy is grounded on respect for patients' ability to take responsibility for their own life ${ }^{11}$ and, from their experiences and expressions, participation is an extended concept that depends on internal as well as external circumstances. ${ }^{12}$ Participation can also be a dynamic process that is integral to the work of nurses and their patients ${ }^{13}$ and demands dialogue, information and knowledge about patients' situations. ${ }^{14}$

Patient records constitute a basis for and are important in communication between health care professionals and patients. ${ }^{15}$ Patient participation is dependent on what these professionals know about individual patients' wishes. The nurses and physicians responsible for patients are supposed to inform them individually, in a suitable way, about the different methods that are available for examination, care and treatment. The information that patients receive should be documented in their health care records and correspond to the type of health care the patients want and what they actually receive. ${ }^{16,17}$

Traditional palliative care has previously been focused on patients with incurable cancer, whereas currently this concept now includes all patients with palliative needs. Most definitions of palliative care put more emphasis on relieving suffering and providing comfort and less on curing disease. ${ }^{18,19}$ This research concerning care at the end of life describes a special time, when life is ending. Details of patients' participation in their own end-of-life care should be adequately documented in their health care records, but unfortunately limited knowledge is available in this area.

\section{Aim}

The aim of this study was to describe how patients' participation in the care they received in the last three months of their life was documented in their health care records.

\section{Method}

The present qualitative study is part of a larger project that used a descriptive design to investigate patients' situation at the end of life. This was carried out in the county 
of Västra Götaland, Sweden, during 2003 to survey facts about the prevalence, distribution and inter-relationship of certain conditions, various health problems and symptoms among individuals at the end of life. The survey included demographic and social conditions, the use of health care resources, morbidities and co-morbidities, symptoms and problems identified, technologies and treatment modalities used, information related to the transition to death, and patients' level of participation in their end-of-life care. This retrospective study started with a review of death certificates, after which health care records (medical and nursing) were examined in order to explore the research question.

\section{Participants}

The county of Västra Götaland consists of 49 municipalities, of which the total population was 1500857 in 2001. The mortality rate was 15869 (8136 women and 7733 men). ${ }^{20}$ For the present study the criteria for inclusion were: those who had died in the county of Västra Götaland during 2001, who were aged 18 years or more at the time of death, and who had received health care services under the Health and Medical Service Act during the last three months of their life. The exclusion criteria were: those who had died suddenly and/or no health care services were related to the death, accidental death or suicidal death.

Two hundred and eighty records were selected from a primary sample. Eighteen were excluded according to the study criteria, the persons having died suddenly, in accidents or by committing suicide. Eight were excluded because no health care services were rendered during the last three months of life. Twenty-five individuals were excluded because medical and/or nursing records were inaccessible because of administrative routines. The final study sample consisted of 229 individuals.

The patients lived either at home or in residential care facilities. They temporarily and to various extents used different care facilities during the last months of their lives. About half of the participants died in hospital and the other half died in residential care facilities, their own homes, hospices or a private health care facility. Only $9 \%$ died in their own homes.

The patients had many different diagnoses and problems during this period. The most prevalent diagnoses were: tumours, congestive heart failure, hypertension, diabetes, dementia, sequelae of stroke, ischaemic heart disease, chronic atrial fibrillation, peripheral vascular disease, pulmonary disease, musculoskeletal disease, psychiatric problems, and gastrointestinal, liver, kidney and urinary tract diseases. The symptoms most frequently described were pain and fatigue, closely followed by general weakness, urinary incontinence, anxiety, appetite problems, dyspnoea, sleep problems, skin irritation and sores, oedema, shortness of breath, plus more unusual problems. The diagnoses and symptoms varied; some patients had only a few but the majority had several diagnoses/symptoms during the last three months of their life.

\section{Data collection}

The records were obtained via the patient administrative system of all the health care units visited by the patients during the last three months of their 
life. Consequently, some patients had three or four separate records, while others had only one. All data relevant to the patients' last three months of life were collected.

Two researchers worked together during the whole period of data collection and a third researcher participated in two municipalities for a shorter time. Data from the documentation referring to how the patients participated in their daily life, their place of residence, and the pain relief, medical treatments and examinations they received were transcribed with the help of an assessment tool based on the World Health Organization (WHO) definitions of functioning, disability and health. ${ }^{10}$ The assessment tool was tested at different health care units before acceptable inter-rater reliability was reached between the researchers (92.5\%). The tests were implementd by using 20 records from different units. These were examined by all three researchers and assessed according to the tool.

\section{Data analysis}

A method of content analysis described by Krippendorff $^{21}$ was used because of its suitability for analysing these types of texts. Content analysis of textual material is an established method. The text used in this analysis was extracted from the deceased patients' health care records and described the various ways in which these people had participated in the care they had received during the last three months their of life.

The content analysis was derived inductively from the texts. These texts were extracted from the relatively short text units in the records. The analysis was carried out using five steps: first the whole record was read in order to capture content that matched the aim of this article; second, the text was condensed into meaning units corresponding with the actual content. Although the records themselves were sometimes condensed descriptions of the patients' conditions, such texts were sometimes used word for word as a meaning unit. Some longer descriptions were condensed to form meaning units. Third, analysis of these meaning units was used to formulate codes, followed by the fourth step of comparing the codes and reducing them; similar codes were then summarized. Four categories emerged from the codes, elicited from condensed text taken from the health care records. These categories describe the different ways in which the patients had participated in their own care.

\section{Ethical considerations}

Vulnerable groups, such as people who are dying, must be handled with great care and respect; all the researchers working with this study were well aware of this. The ethical dilemma in this study was that, when using the medical and nursing records of deceased patients, it is impossible to secure informed consent. It was therefore of the utmost importance to remove all identifying information. The content of these deceased patients' health records cannot be verified by the people concerned, so it is imperative to emphasize that the study deals specifically with health care professionals' documentation regarding the patients' participation in the care provided at the end of their life. The study was designed as a retrospective research project in which all accessible health care records kept during the patients' 
last three months of life were used. All patient documents are regulated by Swedish law and special requirements for using this information must be fulfilled. ${ }^{16}$ Permission to use patient data was granted by the municipalities and the various health care facilities. The Ethics Committee of Göteborg University approved the study (Ö633-02).

\section{Findings}

The findings show that documentation concerning these patients' participation in their own care was described in more than half of the records (58\%). Some records contained only one documentation of patients' involvement, while in others several situations were noted. Furthermore, documentation in the health care records included the specific proceedings in which the patients were involved at that particular time.

Four categories describe the different ways in which the patients' participated: refusing offered care and treatment, appealing for relief, desires for everyday life, and making personal decisions. Table 1 illustrates the process of analysis of texts to the definition of categories.

Table 1 Process of analysis of texts to definition of categories

\begin{tabular}{|c|c|c|c|}
\hline Text from records & Condensation & Code & Category \\
\hline $\begin{array}{l}\text { The patient does not want } \\
\text { food or drink }\end{array}$ & $\begin{array}{l}\text { Does not want food } \\
\text { or drink }\end{array}$ & Refusing & $\begin{array}{l}\text { Refusing offered } \\
\text { care and treatments }\end{array}$ \\
\hline $\begin{array}{l}\text { The patient spits out the } \\
\text { medication }\end{array}$ & Spits out medication & & \\
\hline $\begin{array}{l}\text { The patient refuses mouth } \\
\text { care }\end{array}$ & Refuses mouth care & & \\
\hline $\begin{array}{l}\text { The patient appeals for pain } \\
\text { relief }\end{array}$ & $\begin{array}{l}\text { Appealing for pain } \\
\text { relief }\end{array}$ & Appealing & $\begin{array}{l}\text { Appealing for } \\
\text { relief }\end{array}$ \\
\hline $\begin{array}{l}\text { The patient appeals for } \\
\text { something for sleeping }\end{array}$ & $\begin{array}{l}\text { Appealing for } \\
\text { sleeping pills }\end{array}$ & & \\
\hline $\begin{array}{l}\text { The patient is begging } \\
\text { constantly for help }\end{array}$ & $\begin{array}{l}\text { Begging constantly } \\
\text { for help }\end{array}$ & & \\
\hline $\begin{array}{l}\text { The patient wants to go home } \\
\text { and eventually discusses } \\
\text { home nursing help }\end{array}$ & Wanting to go home & Desiring & $\begin{array}{l}\text { Desires for } \\
\text { everyday life }\end{array}$ \\
\hline $\begin{array}{l}\text { The patient wishes to go to } \\
\text { the hospital }\end{array}$ & $\begin{array}{l}\text { Wishing to go to the } \\
\text { hospital }\end{array}$ & & \\
\hline $\begin{array}{l}\text { The patient is longing for a } \\
\text { room companion }\end{array}$ & Longing for company & & \\
\hline $\begin{array}{l}\text { The patient has morphine } \\
\text { medication that she takes } \\
\text { herself }\end{array}$ & $\begin{array}{l}\text { Desires deciding } \\
\text { when to take the pain } \\
\text { relief drugs }\end{array}$ & Self-determination & $\begin{array}{l}\text { Making personal } \\
\text { decisions }\end{array}$ \\
\hline $\begin{array}{l}\text { In agreement with the patient } \\
\text { we decide not to start with } \\
\text { cancer therapy }\end{array}$ & $\begin{array}{l}\text { In agreement with the } \\
\text { patient, decide on no } \\
\text { therapy }\end{array}$ & Co-determination & \\
\hline
\end{tabular}




\section{Refusing offered care and treatments}

Refusing offered care and treatments was the most common documentation regarding patients' participation in their care at the end of their life. Refusals were written as declining, rejecting, not wanting to, opposing, refusing and not receiving, and also locking doors, biting, compressing lips and spitting. The patients refused to eat and drink, receive care, take drugs, allow medical examinations, receive treatments, use technical facilities, communicate, change rooms, contact family members and perform everyday activities. The most typical written comment regarding refusal was of patients refusing everything that was put in their mouth (food, drink and medications).

\section{Appealing for relief}

Appealing for relief was almost exclusively related to pain relief. In a few cases appealing was mentioned as the desire to be given medication for anxiety and sleep problems. The documentation showed clearly the special ways the patients had of participating in their own care and treatment. The concepts that were used for appealing were begging, crying, complaining, moaning and making bodily gestures. The most common description was 'the patient requests pain relief'. This was mainly for pain relieving medication, but sleeping pills and sedatives were also noted. In a few cases patients appealed for help in general.

\section{Desires for everyday life}

Desire for activities of everyday life was described as wanting, wishing, longing for, asking for, requesting, seeking for, being positive and concerned about. These desires dealt mostly with future actions and were documented as wanting to stay at home or in hospital during this last period of their life. A typical example was 'the patient wishes to go home and is positive about having home health care'. Other desires dealt with mobilization, contact with the family, technical facilities and wanting to decide on personal day and night rhythms, but they were also related to medical treatments and examinations. The descriptions in this category represent more diverse situations corresponding to common events that occur in everyday life.

\section{Making personal decisions}

The category of making personal decisions describes the patients' participation as being able to make their own decisions personally or together with others. The patients decided, alone or together with others, what to eat, which treatment to receive, when to go to the hospital, when to call the doctor, or where they would live at the end of their life. These descriptions were sparsely documented but there was variation in the heath care professionals' notes about the patients' personal decisions (eg their own requests, making their own calls, implementing decisions, deciding in consultation with others, and deciding together). Further examples were 'the patient decides what to drink' or 'the patient together with the doctor decided to stop further cancer treatments'. 


\section{Discussion}

The aim of this study was to describe how patients' participation in their care was documented in their health care records during their last three months of their life. The patients' participation was not documented at all in $42 \%$ of the available cases; the remainder varied from just one example to several. Kirchhoff et al. ${ }^{22}$ and others ${ }^{15,23,24}$ found a lack of comprehensive documentation of health care given at the end of life. However, the data available for this study were collected from health care records representing a period of three months, which provided a richer base of material than earlier studies.

The patients' participation was described in different ways, depending on the activity involved. The most common way for patients to participate in their end-of-life care was described as refusing care and treatments. This negative way of patient participation is a constitutional right ${ }^{25}$ and the most common examples found in this study were refusing food and fluids. This can shorten patients' lives ${ }^{26-28}$ and is often described as being their way of hastening death. ${ }^{29}$ This resistance to being involved at the end of life may be regarded as dissociation from offered health care.

Appealing for relief was the second way in which the patients' participation was documented in the health care records. This has not been found in previous studies. The demand for relief, especially pain relief, shows a more dependent patient role. Dependency as documented by health care professionals in these situations reflects patients' vulnerability because they no longer have the necessary knowledge or the key to the medicine cabinet. These findings are supported by other empirical studies. For example, Strandberg et al. showed that when patients ask for pain relief they cannot then refuse or make their own decisions because they must rely on the professionals giving them the care and treatment on which they depend. ${ }^{30}$ Lomborg et al. found that these patients are concerned about being good patients in order to gain health care professionals' sympathy to enable them to cope with the dependency. ${ }^{31}$

A third way of patients' participation in their care was noted as wanting to collaborate with nurses and doctors. Desires can be seen as being rather like a dialogue with health care professionals and may represent more a need for co-operative communication than refusing and appealing for relief or an expression of codetermination. $^{32}$ In these situations the documentation showed that the patients' desires concerning ordinary life situations were future orientated. It is important to follow patients' desires as they change during an illness trajectory and move through the stages of dying and death. ${ }^{33}$

Making personal decisions was the fourth method of patients' participation, but this was sparsely described in the records and dealt with a range of situations. This is associated with the concepts self-determination and co-determination described by Sahlberg-Blom, which are different from participation and co-operation. ${ }^{8}$

The various ways in which these patients participated in making decisions about their own health care at the end of their life depended on the type of activities in which they were involved. The same patients were described as refusing, appealing and expressing their desires. If the description was about an everyday life event, then participation was described as refusal. When they were dependent and vulnerable, as when in pain, they were described as appealing for relief. In the descriptions relating to wishes, more diverse situations were expressed, which corresponded with the elements of everyday life. The closer the patients were to death the fewer 
documentations described them as participating in their own health care and treatments.

How patients participate and become involved in different activities during their last three months of life according to the WHO definitions give way to questions such as what it means to be involved when life is ending. The most common way for patients to participate in their end of life care described in health care records was to refuse offered care and treatments. Is this an expression of the health care professionals' poor assessment of patients' needs, or is it indeed a healthy reaction from the patients to show clearly what they want? Refusing does show clearly what one wants, while appealing is a more powerless expression. The documentation that described the patients as wanting and deciding articulates a more collaborative way of sharing different proceedings.

\section{Limitations}

A limitation of this study could be that the documentation in the health care records did not cover the patients' expression of their needs, but rather the health care professionals' interpretation of these needs. Some previous studies ${ }^{15,23,24}$ have also shown a discrepancy between patients' actual experiences of their problems/ symptoms and the notes made in patients' records.

\section{Conclusions}

Patient participation is usually described as a positive co-operative statement, but this study shows that documentation regarding patients' involvement in their own care and treatments at the end of their life can be described more as something that the patient must appeal for or refuse to do. The findings indicate that documented participation in care at the end of life is mostly described as a rejected codetermination, so that patients have to say no to offered care and treatments. Involvement in decisions about these patients' health care at the end of their life was documented more often as dissociation from offered health care than as the giving of consent.

\section{Acknowledgements}

We are grateful to Sven Arvidsson, Director, and Tommy Sonestedt, Auditor, at the Audit Department at the County Council of Västra Götaland for help with coordination of the data collection. We are also grateful to the people of the County Council of Västra Götaland and the participating municipalities who made the data collection possible.

Irma Lindström and Ella Danielson, The Sahlgrenska Academy at Göteborg University, Göteborg, Sweden.

Fannie Gaston-Johansson, The Sahlgrenska Academy at Göteborg University, Göteborg, Sweden, and Johns Hopkins University, Baltimore, USA. 


\section{References}

${ }^{1}$ Hälso och sjukvairdslagen (SFS 1982:763). (The Health and Medical Service Act.) Ministry of Health and Social Affairs in Sweden, 1982 [in Swedish].

2 Statens offentliga utredningar. (Swedish Government Official Reports.) (SOU 1997:154) Patienten har rätt. (Patients have rights.) National Board of Health and Welfare in Sweden, 1997 [in Swedish].

${ }^{3}$ Weisman AD. The realization of death. A guide for the psychological autopsy. Jason Aronson, 1974.

${ }^{4}$ Steinhauser KE, Christakis NA, Clipp EC, McNeilly M, McIntyre L, Tulsky JA. Factors considered important at the end of life by patients, family, physicians, and other care providers. JAMA 2000; 15: 2476-82.

5 Pierce PF, Hicks FD. Patients' decision-making behaviour. Nurs Res 2001; 50: 267-74.

${ }^{6}$ Davidson BJ, Degner LF. Promoting patients' decision-making in life-and-death situations. Semin Oncol Nurs 1998; 14: 129-36.

7 Nordgren S, Fridlund B. Patients' perception of self-determination as expressed in the context of care. J Adv Nurs 2001; 35: 117-25.

8 Sahlberg-Blom E. Autonomy, dependency and quality of life. The last month of life for 56 cancer patients [Dissertation]. Acta Universitatis Upsaliensis, 2001.

9 Sainio C, Lauri S. Cancer patients' decision-making regarding treatment and nursing care. J Adv Nurs 2003; 41: 250-60.

10 World Health Organization. International classification of functioning, disability and health (ICF). 2001. Retrieved 2 August, 2005, from: http://www.who.int/classifications/icf/en/

11 Randers I, Mattiasson A-C. Autonomy and integrity: upholding older patients' dignity. J Adv Nurs 2004; 45: 63-71.

12 Eldh A-C, Ehnfors M, Ekman I. The phenomena of participation and non-participation in health care - experiences of patients attending a nurse-led clinic for chronic heart failure. Eur J Cardiovasc Nurs 2004; 3: 239-46.

13 Tutton EMM. Patient participation on a ward for frail older people. J Adv Nurs 2005; 50: 143-52.

14 Ramfelt E, Lützén K. Patients with cancer: their approaches to participation in treatment plan decisions. Nurs Ethics 2005; 12: 143-55.

15 Ehrenberg A, Ehnfors M. The accuracy of patient records in Swedish nursing homes: congruence of record content and nurses and patients' descriptions. Scand J Caring Sci 2001; 15: 303-10.

16 Patientjournallagen (SFS 1993:20). (Regulations and advisory instructions on the Patient Record Act.) Ministry of Health and Social Affairs in Sweden, 1993 [in Swedish].

17 Ehnfors M. Nursing documentation practice on 153 hospital wards in Sweden as described by nurses. Scand J Caring Sci 1993; 7: 201-207.

18 World Health Organization. Definition of palliative care. 2005. Retrieved 2 August, 2005, from: http://www.who.int/cancer/palliative/definition/en/

19 Abu-Saad HH. Palliative care: an international view. Patient Educ Couns 2000; 1: 15-22.

20 Statistics Sweden. Befolkningsstatistik. (Population statistics.) Statistics Sweden, 2004 [in Swedish].

${ }^{21}$ Krippendorff, K. Content analysis - an introduction to its methodology. SAGE, 2004.

22 Kirchhoff KT, Anumandla PR, Foth KT, Lutes SN, Gilbertson-White SH. Documentation on withdrawal of life support in adult patients in the intensive care unit. Am J Crit Care 2004; 13: 328-34.

${ }^{23}$ Strömgren AS, Groenvold M, Sorensen A, Andersen L. Symptom recognition in advanced cancer. A comparison of nursing records against patient self-rating. Acta Anaesthesiol Scand 2001; 45: 1080-85.

24 Strömgren AS, Groenvold M, Pedersen L, Olsen AK, Spile M, Sjogren P. Does the medical record cover the symptoms experienced by cancer patients receiving palliative care? A comparison of the record and patient self-rating. J Pain Symptom Manage 2001; 21: 189-96. 
25 Hosay CK. Compliance with patients' end-of-life wishes by nursing homes in New York City with conscience policies. Omega 2002; 44: 57-76.

${ }^{26}$ Harvath TA, Miller LL, Goy E, Jackson A, Delorit M, Gantini L. Voluntary refusal of food and fluids: attitudes of Oregon hospice nurses and social workers. Int J Palliat Nurs 2004; 10: 236-41.

27 Borasio GD, Weltermann B, Voltz R, Reichmann H, Ziers S. Einstellungen zur Patientenbetreuung in der letzten Lebensphase. Eine Umfrage bei neurologischen Chefärtzen. (Attitudes towards patient care at the end of life. A survey of directors of neurological departments.) Nervenarzt 2004; 75: 1187-93 [in German].

28 Ashby MA, Mendelson D. Gardner; re BWV: Victorian Supreme Court makes landmark Australian ruling on tube feeding. Med J Aust 2004; 181: 442-45.

29 Altun İ, Ersoy N. Undertaking the role of patient advocate: a longitudinal study of nursing students. Nurs Ethics 2003; 10: 462-71.

30 Strandberg G, Norberg A, Jansson L. Meaning of dependency on care as narrated by 10 patients. Res Theory Nurs Pract 2003; 17: 65-84.

31 Lomborg K, Bjorn A, Dahl R, Kirkevold M. Body care experienced by people hospitalized with severe respiratory disease. J Adv Nurs 2005; 50: 262-71.

32 Sahlberg-Blom E, Ternestedt B-M, Johansson J-E. Patient participation in decision making at the end of life as seen by a close relative. Nurs Ethics 2000; 7: 296-313.

33 Brown M, Grbich C, Maddocks I, Parker D, Roe P, Wills E. Documenting end of life decisions in residential aged care facilities in South Australia. Aust N Z J Public Health 2005; 29: 85-90. 
Copyright of Nursing Ethics is the property of Arnold Publishers and its content may not be copied or emailed to multiple sites or posted to a listserv without the copyright holder's express written permission. However, users may print, download, or email articles for individual use. 